\title{
Jurnal
}

\section{Prediction of the Solubility of Caffeic ACID IN WATER Using AN ACTIVITY COEfFICIENT MODEL}

\author{
Mohd Shukri Mat Nora,b, Zainuddin Abd Manana,b*, Azizul Azri \\ Mustaffaa,b, Chua Lee Suanb,c
}

aprocess Systems Engineering Centre (PROSPECT), Research Institute of Sustainable Environment (RISE), Universiti Teknologi Malaysia, Malaysia

bFaculty of Chemical and Energy Engineering, Universiti Teknologi Malaysia, Malaysia

cInstitute of Bioproduct Development (IBD), Universiti Teknologi Malaysia, Malaysia
Article history

Received

23 May 2015

Received in revised form

12 November 2015

Accepted

22 December 2015

*Corresponding author zain@cheme.utm.my

\section{Graphical abstract}

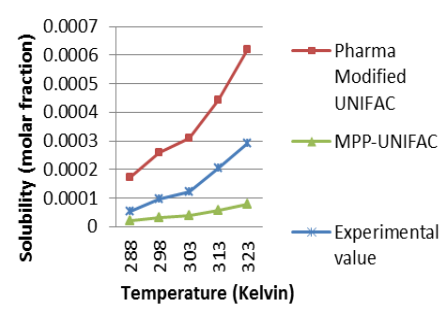

\begin{abstract}
Solubility of solid compounds is one of the most widely used physicochemical properties in chemical engineering design and experiments. Experimental works for solubility are not always possible because of the small amount of yield available in the phytochemicals extraction. Thus, one interesting perspective is the used of thermodynamic models, which are usually employed for predicting the activity coefficients in the case of solid-liquid equilibria (SLE). Phytochemical compound used in this study is caffeic acid where a comparative study of the MPP-UNIFAC and Pharma Modified UNIFAC were used to predict the solubilities of this phytochemical. The performances of these two activity coefficient models were compared using the experimental solubilities data obtained from the literature in the temperature range of 288 to $323 \mathrm{~K}$ and were evaluated by analysing the absolute relative errors (ARE) between the experimental and the predicted values. Moreover, the model errors were also discussed according to the functional groups of the molecules and water as the solvent. In general, the MPP UNIFAC showed better accuracy as compared to the Pharma Modified UNIFAC in predicting the solubility of caffeic acid in water. Nevertheless, both models give very poor qualitative predictions.
\end{abstract}

Keywords: Solubility prediction, activity coefficient, UNIFAC

(C) 2016 Penerbit UTM Press. All rights reserved

\subsection{INTRODUCTION}

Caffeic acid ((E)-3-(3,4-dihydroxyphenyl)- prop-2enoic acid) is a phytochemical belonging to the family of phenolic acids. Solvent extraction is usually applied in isolating this phytochemical, where the yield of extracts is influenced by solubility behavior of the compound and selected solvent. Meanwhile, the solubility of the phytochemical in a given solvent is governed by the thermodynamic factor called the activity coefficient [1]. Activity coefficient is a mixture property that provides a measure of the liquid phase non-ideality. However, studies on the solubility prediction of phytochemicals are very scarce due to the lack of physical property data. The aim of this study is to predict the solubility of caffeic acid in water by testing and analysing the existing activity coefficient models which are MPP-UNIFAC [2] and Pharma Modified UNIFAC [3] at temperature $288 \mathrm{~K}$, $298 \mathrm{~K}, 303 \mathrm{~K}, 313 \mathrm{~K}$, and $323 \mathrm{~K}$. 


\subsection{METHODOLOGY}

\subsection{Data Collection}

Melting point and enthalpy heat of fusion values of caffeic acid were collected from the published literature as reported by Alevizou and Voutsas [4] using Differential Scanning Calorimetre. The experimental solubilities of caffeic acid in pure water at different temperatures were obtained from Mota et al. [5].

All data considered in this study can be seen in Table 1. The structure of this phytochemical compound is shown in Figure 1.

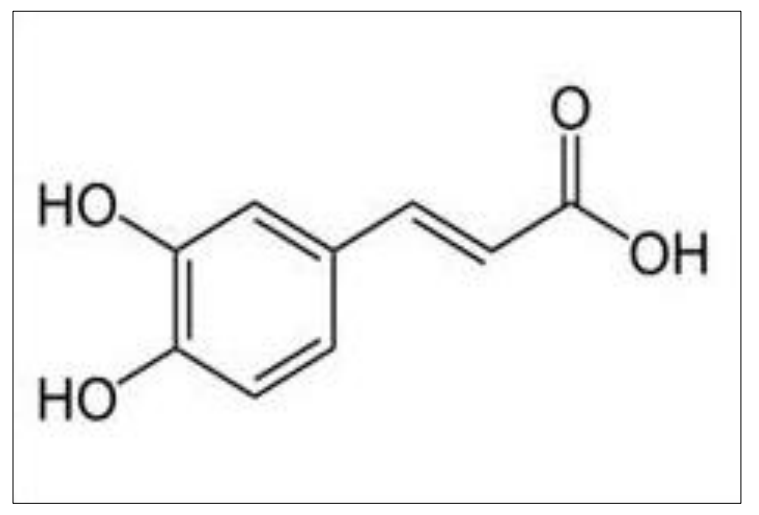

Figure 1 Structure of caffeic acid

Table 1 Literature data used in this study

\begin{tabular}{llc}
\hline Properties & Experimental Data & Reference \\
\hline $\begin{array}{l}\text { Melting Point }\left({ }^{\circ} \mathrm{C}\right) \\
\text { at 0.1 MPa }\end{array}$ & $232.5 \pm 0.4$ & {$[4]$} \\
& & \\
Enthalpy heat of & $27.68 \pm 0.13$ & {$[4]$} \\
fusion $\left(\mathrm{kJ} . \mathrm{mol}^{-1}\right)$ at & & \\
0.1MPa & & \\
Solubility $(\mathrm{g} / \mathrm{L})$ & $0.55 \pm 0.01$ at $288 \mathrm{~K}$ & {$[5]$} \\
& $0.98 \pm 0.01$ at $298 \mathrm{~K}$ & {$[5]$} \\
& $1.23 \pm 0.01$ at $303 \mathrm{~K}$ & {$[5]$} \\
& $2.04 \pm 0.02$ at $313 \mathrm{~K}$ & {$[5]$} \\
& $2.92 \pm 0.02$ at $323 \mathrm{~K}$ & {$[5]$} \\
\hline
\end{tabular}

\subsection{Thermodynamic Modeling}

The following standard thermodynamic Eq (1) is applied for the calculation of solid solubility in mole fraction, xi in water.

$$
\chi_{i} \gamma_{i}=\exp \left\{\begin{array}{l}
\frac{\Delta H_{i}^{f u s}}{R T_{m i}}\left(\frac{T-T_{m i}}{T}\right) \\
+\frac{\Delta C_{p i}^{f u s}}{R}\left[\ln \left(\frac{T}{T_{m i}}\right)-\left(\frac{T-T_{m i}}{T}\right)\right]
\end{array}\right\}
$$

where $Y_{i}, \Delta H_{i} f u s$ and Tmi stand for the activity coefficient, the enthalpy of fusion, and the melting temperature of the solid solute respectively. Whereas $\mathrm{T}$ is the temperature, and $\Delta \mathrm{C}_{\mathrm{pi}}$ fus the difference between the heat capacity of the solid and the liquid phase at equilibrium for component i. Gracin et al. [6] have found a small influence of the $\Delta C_{p}$ in UNIFAC model. Therefore, $\triangle \mathrm{C}_{\mathrm{pi}}$ fus contribution is typically assumed as negligible. This Equation (1) can be further simplified to give the relationship between solubility and activity coefficients leading to Eq. (2).

$$
\chi_{i} \gamma_{i}^{l}=\exp \left[\frac{\Delta H_{i}^{f u s}}{R T_{m i}} \ln \left(\frac{T}{T_{m i}}\right)\right]
$$

\subsection{MPP-UNIFAC and Pharma Modified UNIFAC}

The basis of these two models is a combination of two parts of activity coefficient as stated in Eq. (3). . In fact, these models are derivative of developed Modified UNIFAC (Dortmound) model to overcome the limitation of the model when applied to active pharmaceutical ingredient and polyphenol compound solutions. The different between the models resides solely in the set of its unary ( $R_{k}$ and $Q_{k}$ ) and binary parameters values $\Psi_{\mathrm{nm}}(\mathrm{k}, \mathrm{n}$ and $\mathrm{m}$ indices) for some of the functional groups.

$$
\ln \gamma=\ln \gamma^{C}+\ln \gamma^{R}
$$

$\mathrm{Y}^{\mathrm{C}}$ is the combinatorial term, represents the entropic contribution to the activity coefficient which takes into account the shape and size of the molecules. Expression of In $Y^{C}$, as given in Eq. (4) depends on the mole fraction $\left(x_{i}\right)$, area $\left(\Theta_{i}\right)$, segment fraction $\left(\phi_{i}\right)$, Van der Waals radius $\left(r_{i}\right)$ and volume $\left(q_{i}\right)$. Superscript i designates the type of phytochemical:

$$
\ln \gamma_{i}^{C}=1-\ln \frac{\Phi_{i}}{x_{i}}+5 q_{i}\left(1-\ln \frac{\Phi_{i}}{\theta_{i}}+\ln \left(\frac{\Phi_{i}}{\theta_{i}}\right)\right)
$$

Meanwhile, $Y^{R}$ is the residual part which represents the enthalpic contribution (inter and intramolecular interactions). It is a sum of the activity coefficients of the functional groups weighted by their number in solution. The equation for this part is presented in Eq. (5).

$\ln \gamma_{i}^{R}=\sum_{k} v_{k}^{(i)}\left[\ln \Gamma_{k}-\ln \Gamma_{k}^{(i)}\right]$

where $u_{k}$ and $u_{k}^{i}$ are the number of groups of type $k$ in the mixture and in component $i$. $\Gamma_{k}$ and $\Gamma_{k} k$ are the residual activity coefficient of group $k$ in the mixture and in a solution of pure component i respectively. They depend on the area and segment fraction of the compounds and adjustable binary interaction parameters $a_{m n}$ that are usually regressed from VLE experimental data. The equations are expressed in Eq. (6) and Eq. (7): 
$\ln \Gamma_{k}=Q_{k}\left[1-\ln \left(\sum_{m} \Theta_{m} \psi_{m k}\right)-\frac{\sum_{m} \Theta_{m} \psi_{k m}}{\sum_{n} \Theta_{n} \psi_{n m}}\right]$

with:

$\psi_{m n}=\exp \left(\frac{a_{m n}+b_{m n} T+c_{m n} T^{2}}{T}\right)$

\subsection{Evaluation of the Models}

The absolute relative error (ARE) was calculated for each method in order to evaluate the performance of these three models. The ARE value was determined using Eq. (10):

$$
A R E=\left|\frac{\chi_{\exp }-\chi_{\text {pred }}}{\chi_{\exp }}\right| \times 100 \%
$$

\subsection{RESULTS AND DISCUSSION}

Figure 2 shows the performance of the two models by comparing them with the experimental values. The predictions made with both models underestimated the solubility of the caffeic acid. The ARE values as in Table 2 shows that the MPP-UNIFAC yields ARE value of $60 \%$ (288 K), $67.11 \%(298 \mathrm{~K}), 68.16 \%$ (303 K), 72.33 (313 K), and $72.73 \%$ (323 K) whereas Pharma Modified UNIFAC yields ARE value of $215.62 \%$ (288 K), 161.89\% (303 K), 151.41\% (303 K), 116.47\% (313 K) and $111.67 \%(323 \mathrm{~K})$.

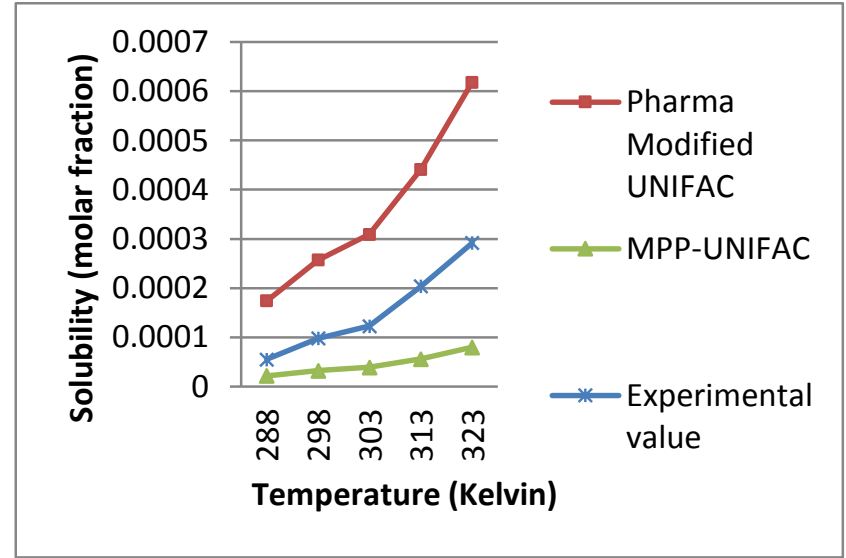

Figure 2 Comparison between experimental solubility of caffeic acid and prediction made by Pharma Modified UNIFAC and MPP-UNIFAC in water

The poor prediction showed by Pharma-Mod is because of the unavailable interaction parameter values for $\mathrm{m}$ and $\mathrm{n}$ indices in binary parameters values $\Psi_{\mathrm{nm}}$. While the poor prediction of the MPP-
UNIFAC is because of the missing values of the "aC$\mathrm{CH}=\mathrm{CH}$ " functional group in the unary and binary parameters data, also some of the new interaction parameter values which have been proposed by the authors are not validated with a larger set of data.

Table 2 Absolute Relative Error shown by MPP-UNIFAC and Pharma Modified UNIFAC

\begin{tabular}{lcc}
\hline Temperature & $\begin{array}{l}\text { MPP-UNIFAC, } \\
\text { ARE (\%) }\end{array}$ & $\begin{array}{l}\text { Pharma Modified } \\
\text { UNIFAC, ARE (\%) }\end{array}$ \\
\hline 288 & 60 & 215.62 \\
298 & 67.11 & 161.89 \\
303 & 68.16 & 151.41 \\
313 & 72.33 & 116.47 \\
323 & 72.73 & 111.67 \\
\hline
\end{tabular}

\subsection{CONCLUSION}

In the present work, the capabilities of two thermodynamic models to predict the phytochemical solubility of caffeic acid in water was investigated. Work is in progress to increase the prediction accuracy of the models to reduce the ARE value down to within $5 \%$.

\section{Acknowledgement}

The authors gratefully acknowledge the Ministry of Higher Education (Malaysia) and Universiti Teknologi Malaysia for the funding provided for this research under the Fundamental Research Grant Scheme (Reference: R.J130000.7844.4F270).

\section{References}

[1] J. Q. António, F. L. Mota, S. P. Pinho, E. A. Macedo. 2009. Solubilities Of Biologically Active Phenolic Compounds: Measurements And Modelling. Journal of Physical Chemistry B. 113(11): 3469-3476.

[2] D. M. Sevillano, L. A. M. van der Wielen, N. Hooshyar, M. Ottens. MPP-UNIFAC, A Predictive Activity Coefficient Model For Polyphenols. 2014. Fluid Phase Equilibria. 384: 82-88.

[3] Diedrichs, A., \& Gmehling, J. 2011. Solubility Calculation Of Active Pharmaceutical Ingredients In Alkanes, Alcohols, Water And Their Mixtures Using Various Activity Coefficient Model. Industrial and Engineering Chemistry Research. 50(3): 1757-1769.

[4] E. I. Alevizou, E. C. Voutsas. 2013. Solubilities of p-coumaric And Caffeic Acid In Ionic Liquids And Organic Solvents. The Journal of Chemical Thermodynamics. 62: 69-78.

[5] F. L. Mota, A. J. Queimada, S. P. Pinho, E. A. Macedo. 2008. Aqueous Solubility Of Some Natural Phenolic Compounds. Industrial and Engineering Chemistry Research. 47(15): 5182-5189.

[6] S. Gracin, T. Brinck, A. Rasmuson. 2002. Prediction Of Solubility Of Solid Organic Compounds In Solvents By UNIFAC. Industrial \& Engineering Chemistry Research. 41: $5114-5124$. 